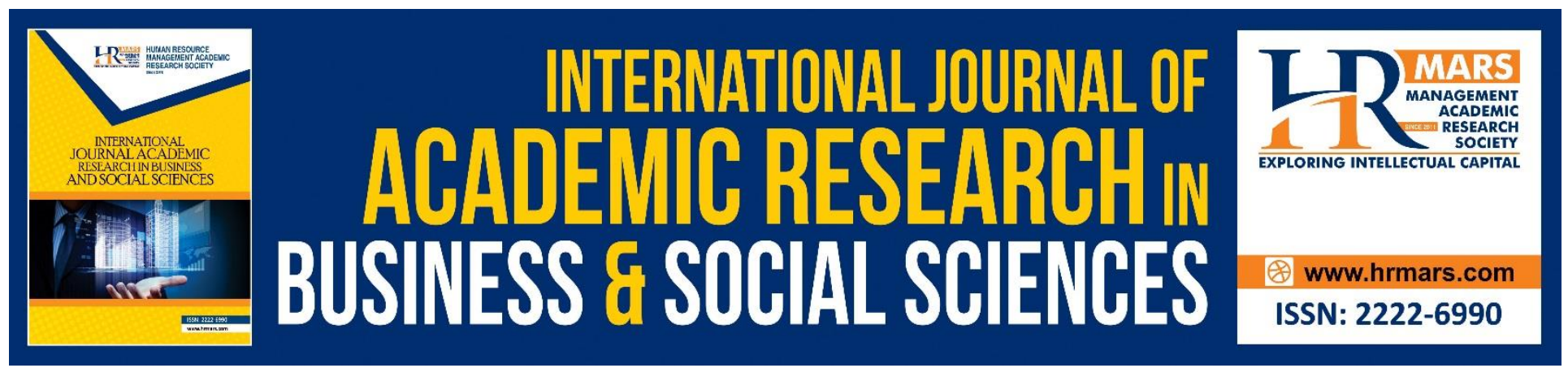

\title{
Developing Measures of Dialogic Communication on Organizational Change: An Exploratory Study
}

Syed Jamal Abdul Nasir Syed Mohamad, Roshidi Hassan, Norlida Abdul Hamid, Ahmad Syahmi Ahmad Fadzil

To Link this Article: http://dx.doi.org/10.6007/IJARBSS/v9-i6/5978

DOI: 10.6007/IJARBSS/v9-i6/5978

Received: 01 April 2019, Revised: 12 May 2019, Accepted: 05 June 2019

Published Online: 28 June 2019

In-Text Citation: (Mohamad, Hassan, Hamid, \& Fadzil, 2019)

To Cite this Article: Mohamad, S. J. A. N. S., Hassan, R., Hamid, N. A., \& Fadzil, A. S. A. (2019). Developing Measures of Dialogic Communication on Organizational Change: An Exploratory Study. International Journal of Academic Research in Business and Social Sciences, 9(6), 640-652.

Copyright: (C) 2019 The Author(s)

Published by Human Resource Management Academic Research Society (www.hrmars.com)

This article is published under the Creative Commons Attribution (CC BY 4.0) license. Anyone may reproduce, distribute, translate and create derivative works of this article (for both commercial and non-commercial purposes), subject to full attribution to the original publication and authors. The full terms of this license may be seen

at: http://creativecommons.org/licences/by/4.0/legalcode

Vol. 9, No. 6, 2019, Pg. 640 - 652

http://hrmars.com/index.php/pages/detail/IJARBSS

JOURNAL HOMEPAGE

Full Terms \& Conditions of access and use can be found at http://hrmars.com/index.php/pages/detail/publication-ethics 


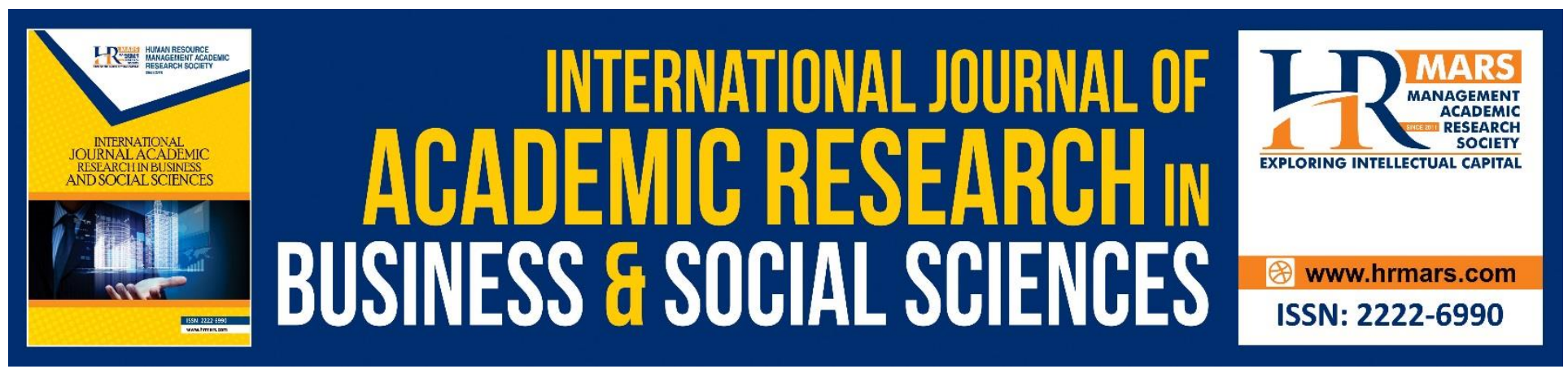

\title{
Developing Measures of Dialogic Communication on Organizational Change: An Exploratory Study
}

\author{
Syed Jamal Abdul Nasir Syed Mohamad¹, Roshidi Hassan², Norlida \\ Abdul Hamid ${ }^{3}$, Ahmad Syahmi Ahmad Fadzil ${ }^{4}$ \\ Arshad Ayub Graduate Business School ${ }^{1,2,3}$, Faculty of Business and Management ${ }^{4}$, \\ Universiti Teknologi MARA (UiTM), Malaysia
}

\begin{abstract}
The purpose of this paper is to develop and validate a dialogic communication scale on the setting of organizational change. This scale can be served as a basis for the assessment of dialogic communication from the employees' perspective Based on the previous literature, this study conceptualized the construct of dialogic communication into five dimensions and generated an initial measurement of 20 items. The samples empirical data obtained was used to analyze the empirical validation of dialogic communication construct according to its underlying dimensionality. Findings developed 16 items scale that measured the five dimensions. A tentative norm of dialogic communication scale is presented while the scale's theoretical and practical applications were also discussed. In conjunction with past recommendations, this study pioneered the effort of developing a quantitative dialogic communication scale that is hopeful to bolster the effective communication effort in organizational change. Additionally, the findings offer sound theoretical development of dialogic communication.
\end{abstract}

Keywords: Dialogic Communication, Organizational Change, Communication, Resistance to Change, Change Management

\section{Introduction}

In relation to organizational change, communication is paramount for the policymakers in ensuring successful change. An organization needs to be alert to the broad provisions and communications tools, approaches and strategies available when making a change since the nature of communication will influence the change initiatives (Johansson \& Heide, 2008). It was proven that communication management and organizational change are inextricably related (Flower, 1962). Though there are many methods of communication, the importance of having dialogic communication in organizational change has always been recommended in the past (Jasmin et al., 2014) and in the present research (Plewes, 2014). The previously mentioned studies found that communication influences the organizational change process. Additionally, it was mentioned throughout the literature that change is a communicative challenge (Matos \& Mark, 2014). Nevertheless, many 
studies still need to be done in the communication of change as it is not merely just an action to convey messages but also a medium to facilitate a change. An effective communication on change should not just be a tool to exchange messages but should be imbued with strong humanistic elements. Messages will be conveyed with stronger means and the longevity of what to be conveyed will be greater through a good change communication. Recently, it was proven qualitatively that change can be effectively managed by adopting a dialogic communication approach (Heuvel et al., 2016). The elements of dialogic communication were found to have correlations towards a successful change (Lawrence, 1954). On this present time, however, there is a paucity of research on how communication nature influences change process (Heuvel et al., 2016). Thus, this research is particular in highlighting the establishment of measurement and validation scale for dialogic communication construct. The outcome of what dialogic communication can do to organization change is worthy to be further study as it can give additional insights to change practitioners in formulating the best and effective communication approach.

\section{Literature Review}

Communication and organizational change are widely discussed since 1950 as the importance of having a good communication have always been recommended in the past research (Buber, 1967; Stewart, 1978; Caldwell, 1993; Botan, 1997; Jasmin et al., 2014). The etymological of word "communication" can be traced back to Latin word "communication" which means to participate, to pool or to take common action (Heuvel et al., 2016). In the present date, there are rich amount of definitions made on communication by many scholars. Although there are many different meanings and depths, the bases to what is communication remain consistent in which communication is the means of conveying a message. Communication can be defined as a social process where people involve deeply in a particular culture, create and exchange meanings, thus addressing the reality of everyday experience.

In the context of change, communication can be defined as informing, involving and motivating collaborators to participate and committed in the change process (Quirke, 1995). Communication also implies the meaning of two processes which information is transmitted and has to be shared (Bakhtin, 1986). However, communication is not just merely for the sake of conveying a message but rather to the joint construction of meaning as a continuous exchange of messages will allow meanings to develop and converge to the point of the establishment of communication where each will share something in common (Heuvel et al., 2016). This implies that messages exchanged have cognitive effects and creation of meaning because the meanings are merely assigned but the exchange will depend on the context which it occurs. Therefore, communication is not limited to verbal or oral communication but in general, communication has broader components such as actions, behaviors and gestures.

Although there are many forms of communication on change, dialogic communication seems to be more effective in managing organizational change (Heuvel et al., 2016; Carpenter et al., 2016). The concept of dialogue is rooted in the philosophy and relational communication theory. This form of communication is dissimilar as compared to the other forms of communications such as "debate", "discussion" or "monologue" (Seow \& Mallika, 2014). As such, dialogic communication is built upon two-way symmetrical communication (Kent \& Taylor, 2002). Although developing a dialogic 
INTERNATIONAL JOURNAL OF ACADEMIC RESEARCH IN BUSINESS AND SOCIAL SCIENCES Vol. 9, No. 6, June, 2019, E-ISSN: 2222-6990 @ 2019 HRMARS

communication can be expensive and time-consuming, it is more effective than a monologic communication. Unfortunately, the theoretical development of the dialogic communication's dimensions still remains undeveloped.

The first research on dialogic communication has outlined five features of dialogic communication; mutuality, propinquity, empathy, risk and commitment (Bruning, Dials \& Shirka, 2008). Mutuality will elevate collaborative orientation promoting co-learning, gauging on understanding on others' positions and fairness. Propinquity involves thorough communication and participation. As such, participants will be communicating at both before and after the decision has been made. Meanwhile, empathy gauges acceptance to those who are in disagreement by practising compassionate orientation. Next, risk refers to the individual's ability to acknowledge uncertainty as part of the process though conveying the risk of a change might alleviates participants' vulnerability to manipulation and uncertainties when disclosing themselves to build the relationship between parties affected. The foundation for the fifth feature is made up of the previous four features. The fifth feature which is the commitment highlights the values of honesty and open participation and a commitment to conversation and interpretation. Recent research explored that in a highly dialogic communication setting, resistance to change was descending (Kent \& Taylor, 2002). In addition, a research based on this type of communication also reveals that the weight of each dimension is different depending on the type of leadership imposed (Seow \& Mallika, 2014).

\section{Mutuality}

Mutuality is referred to "collaboration" and "mutual quality" with the aims of developing a collaborative orientation that will stimulate co-learning, appraising understanding on each other's' positions as well as fairness (Bruning, Dials \& Shirka, 2008). It can also be referred to as recognition by communicators to all affected parties in achieving mutual goals (Seow \& Mallika, 2014). The study found that acknowledgement will influence the support of the communication outcome (Bentley, 2012). In order to facilitate parties to cooperatively working together towards mutual benefit, a strategy should be devised to acknowledge each and every party as a unique contributor to the causes. This mutuality dimension fosters the concept of collaboration and the spirit of mutuality whereby all participants are view as "targets" of change and not "objects of change" (Heuvel et al., 2016). In addition, this concept is vital and very relevant to a change programme that relies heavily on collaboration with a diversity of parties (MacKenzie, Podsakoff \& Podsakoff, 2011).

\section{Propinquity}

Propinquity refers to simultaneous participation and communication (Bruning, Dials \& Shirka, 2008). As such, participants will be communicated both before and after the decision has been made. The engagement with individuals are conducted at present, future and past discussions and this dimension are features based on "immediacy of presence", "temporal flow" and "engagement" (Bruning, Dials \& Shirka, 2008). In another study conducted by Carpenter and colleagues in the reference (Seow \& Mallika, 2014), propinquity emphasizes on awareness of temporality and spontaneity resulted from interactions of involved parties. The immediacy of presence suggested that communication must be conveyed throughout the event of change especially at the present and not just during or after the change. Meanwhile, temporal flow endorsed all participants to share a future 
together and decisions made are considered acceptable by all parties involved while engagement is based upon willingness to commit to the communication while upholding sustainable relationship (Seow \& Mallika, 2014). All in all, propinquity will muster the participative climate during organizational change.

\section{Empathy}

Empathy refers to support and trust that are essentially needed for dialogic communication to exist and this dimension addressed the needs of "supportiveness", "communal orientation" and "confirmation" (Bruning, Dials \& Shirka, 2008). In another study, empathy can define as an act of cultivating a trusting and supportive climate since this dimension emphasizes individuals to seek and understand each other's preferences (Seow \& Mallika, 2014). The study also explained the features of empathy whereby supportiveness will deal with facilitative engagement between leaders and affected groups. As for communal orientation, it can be regarded as how the institution treats the affected individuals whether it is as partners or outsiders. Last but not least, confirmation validates the value of each party's contribution (Seow \& Mallika, 2014).

\section{Commitment}

Commitment refers to "genuineness", "commitment to the conversation" and "commitment to interpretation" while communicating with involved parties (Bruning, Dials \& Shirka, 2008). This dimension thrives on delivering honest and forthright communication. A dialogic relationship needs individuals to share and work based on the same meaning while constantly trying to understand the positions, belief and values of others before their positions can be equitable appraised. In addition, this dimension put forward relationship before outcome (Seow \& Mallika, 2014). From this dimensional perspective, research believes that individuals need to be committed all the way during the dialogue takes place and not to sway to other purposes. Bruning, Dials and Shirka (2008) emphasized that this is the means by which individuals can reach mutually satisfying position.

\section{Risk}

Risk refers to the individual's ability to recognize what they do not know and accepting uncertainty as part of the process as well as the results (Bruning, Dials \& Shirka, 2008). This dimension deals with communicators willingness to engage with parties involved based on their own terms. In doing so, the dialogue will be opened and revealing information that may contradict with the position of the parties involved. Rather than assuming vulnerability of not having the kind of control in communication, this dimension in turns can be a strength in which it can be developed collectively (Heuvel et al., 2016). Parties involved may be vulnerable to criticism and manipulation but accepted solutions from all parties might emerge from the dialogue (Seow \& Mallika, 2014). In practising this dimension, communicators need to not withholding information; rather communicators should disclose the adequate amount of information about the change whether it is favorable or unfavorable depending on the situation. In addition, communicators should seek to learn from parties involved and tend to those who may give uncomfortable responses 


\section{Research Methodology}

The way how this scale was developed for dialogic communication has been much consistent with the study from Hair et al., (2010) scale measurement and validation procedures. The previous measurement for dialogic communication was rather limited mainly because it was only tested on a qualitative setting. The initial items were taken and generated based on the theory and literature to achieve content validity. Data was then collected via purposive sampling technique from public service employees in an education institution who were engaged in organizational change with the leaders practicing dialogic communication. Accordingly, 333 usable set of questionnaires were retained and analyzed. Preliminary data analysis was conducted for data cleaning and data polishing. Next, this study conducted exploratory factor analysis on the measurements followed by internal consistency reliability, convergent validity, discriminant validity and the norm of dialogic communication scale is established.

\section{Data Analysis \\ Content Validity}

Content validity is a qualitative criterion for the evaluation of construct validity (Churchill, 1979) which refers to the extent to which the construct's domains are comprehensively specified and the items of the construct are exhaustedly generated and rigorously purified (Roni, 2014). Accordingly, the initial items were taken and generated strictly based on dialogic communication theory pioneered by Kent and Taylor (2002) as well as the advancement of the theory and literature from (Seow \& Mallika, 2014). Therefore, the conceptualized items fulfilled the content validity requirement.

\section{Preliminary Data Analysis}

Preliminary data analysis is vital to ensure the subsequent analyses are valid (Hair et al., 2017) and not be affected by the unnecessary errors caused by the raw data obtained. The monotone responses were deleted as they posit no value for research. Missing value analysis was conducted via expected maximization (EM) and the missing data was accommodated accordingly. Missing value analysis showed no serious concern for potential bias as the missing data values were all below the permissible threshold value of $20 \%$ (Dancey, 2002). The extreme outlier was also justified as the value shown only one data entry error. Normality check shows that the skewness for the data is -0.831 while the kurtosis is 1.345 . This signifies that the data obtained is normally distributed.

\section{Exploratory Factor Analysis}

Based on the theoretical framework discussed, dialogic communication construct was set to five components which are mutuality, empathy, propinquity, risk and commitment during exploratory factor analysis according to the recommended procedures by (Wong, 2013). The analysis was conducted to determine the statistical dimensionality of each item since the theory is known but not the items. The number of components set to be extracted in SPSS was set to five components which is parallel to the theory of dialogic communication. The analysis in Table 1 shows that all of the five components are accommodated by the coded items. This complied with the measurement of dialogic communication's dimensions by Kent and Taylor (2002). 
INTERNATIONAL JOURNAL OF ACADEMIC RESEARCH IN BUSINESS AND SOCIAL SCIENCES Vol. 9, No. 6, June, 2019, E-ISSN: 2222-6990 @ 2019 HRMARS

Table 1:

Rotated Component Matrix for Dialogic Communication

\begin{tabular}{|l|l|l|l|l|l|}
\hline & \multicolumn{5}{|c|}{ Component } \\
\cline { 2 - 6 } & 1 & 2 & 3 & 4 & 5 \\
\hline Risk3 & 0.85 & & & & \\
Risk4 & 0.83 & & & & \\
Risk2 & 0.80 & & & & \\
Com3 & 0.80 & & & & \\
Risk1 & 0.75 & & & & \\
Com4 & 0.74 & & & & \\
Com1 & 0.73 & & & & \\
Com2 & 0.65 & & & & \\
Emp4 & 0.57 & & & & \\
Mut1 & 0.40 & 0.80 & & & \\
Mut2 & 0.44 & 0.75 & 0.42 & & \\
Mut4 & & 0.70 & & & \\
Mut3 & & 0.65 & 0.42 & & \\
Prop2 & & & 0.81 & & \\
Prop1 & & 0.43 & 0.71 & & \\
Prop3 & & & 0.66 & 0.42 & \\
Emp3 & 0.48 & & 0.55 & 0.44 & \\
Emp1 & & & & 0.77 & \\
Emp2 & 0.53 & & & & \\
Prop4 & 0.51 & & 0.48 & 0.56 & \\
\hline
\end{tabular}

*Abbreviations: Com = Commitment $/$ Emp = Empathy / Mut = Mutuality / Prop = Propinquity

Table 1 shown five components along with the accommodation of items. There were 14 items loaded in the first component, 5 items in the second component, 6 items in the third component, 5 items in the fourth component and two items in the fifth component. The assessment of component 1 (Risk) shown that it was loaded by many measurements. Nevertheless, all of the measurements for risk was presented among the highest values in the component which were Risk3, Risk4, Risk2 and Risk1. The second component (Mutuality) shown that Mut1, Mut2, Mut4 and Mut3 loaded perfectly in component 2. Next, the third component (propinquity) shown loadings of Prop2, Prop1 and Prop3. Since the construct shown the loadings of many propinquity construct, other measurements such as Mut3, Emp3 and Prop4 were disregarded. Next, the fourth component (empathy) shown similar measurement loadings as component 3. Emp3, Emp1 and Emp2 were found loaded in component 3. Lastly, component 5 (commitment) shown only two loadings of Com1 and Com2. Nevertheless, since Com 3 and Com 4 are overlapping on the other component, they are deleted. Therefore, four components were deleted which were Prop4, Emp4, Com3 and Com4 since they were either not presented in their components or measuring multiple components which were contradictory to the theoretical measurement. 
INTERNATIONAL JOURNAL OF ACADEMIC RESEARCH IN BUSINESS AND SOCIAL SCIENCES Vol. 9, No. 6, June, 2019, E-ISSN: 2222-6990 @ 2019 HRMARS

The other items are retained according to their respective components and are tabulated in Table 2 along with the items' statements, item loadings, Cronbach's Alpha, composite reliability and average variance extracted (AVE).

Table 2: Dialogic Communication Constructs' Measurement and Validation

\begin{tabular}{|c|c|c|c|c|c|}
\hline $\begin{array}{l}\text { Item } \\
\text { Code }\end{array}$ & Statement & Loadings & $\begin{array}{l}\text { Cronbach' } \\
\text { s Alpha }\end{array}$ & $\begin{array}{l}\text { Composite } \\
\text { Reliability }\end{array}$ & $\begin{array}{c}\text { Average } \\
\text { Variance } \\
\text { Extracte } \\
\text { d (AVE) }\end{array}$ \\
\hline Mut1 & $\begin{array}{l}\text { I believe that this communication encourages } \\
\text { collaboration }\end{array}$ & 0.924 & & & \\
\hline Mut2 & $\begin{array}{l}\text { I believe that this communication encourages the } \\
\text { spirits of mutuality }\end{array}$ & 0.930 & & & \\
\hline Mut3 & $\begin{array}{l}\text { I believe that I am a target of change and not an } \\
\text { object of change }\end{array}$ & 0.849 & 0.902 & 0.932 & 0.774 \\
\hline Mut4 & $\begin{array}{l}\text { I believe that this communication encourages } \\
\text { diversity of collaborations between affected } \\
\text { parties }\end{array}$ & 0.810 & & & \\
\hline Prop1 & $\begin{array}{l}\text { I believe that this communication acknowledged } \\
\text { my presence throughout the change }\end{array}$ & 0.908 & & & \\
\hline Prop2 & $\begin{array}{l}\text { I believe that this change has been communicated } \\
\text { thoroughly }\end{array}$ & 0.925 & 0.914 & 0.945 & 0.853 \\
\hline Prop3 & $\begin{array}{l}\text { I believe that this communication shared a vision } \\
\text { of change }\end{array}$ & 0.937 & & & \\
\hline Emp1 & $\begin{array}{l}\text { I believe that this communication is supported by } \\
\text { my colleagues }\end{array}$ & 0.927 & & & \\
\hline Emp2 & $\begin{array}{l}\text { I believe that this communication seeks } \\
\text { understanding between affected parties. }\end{array}$ & 0.934 & 0.916 & 0.847 & 0.857 \\
\hline Emp3 & $\begin{array}{l}\text { I believe that this communication honoured } \\
\text { contributions between affected parties }\end{array}$ & 0.915 & & & \\
\hline Com1 & $\begin{array}{l}\text { I believe that this change has been honestly } \\
\text { communicated }\end{array}$ & 0.969 & & & \\
\hline Com2 & $\begin{array}{l}\text { I believe that the communication on this change is } \\
\text { forthright }\end{array}$ & 0.971 & 0.937 & 0.970 & 0.941 \\
\hline Risk1 & $\begin{array}{l}\text { I believe that the communication conveyed the risk } \\
\text { between affected parties }\end{array}$ & 0.889 & & & \\
\hline Risk2 & $\begin{array}{l}\text { I believe that the communication has considered } \\
\text { parties' terms }\end{array}$ & 0.931 & 0.925 & 0.947 & 0.817 \\
\hline Risk3 & I believe that the communication is transparent & 0.919 & & & \\
\hline Risk4 & $\begin{array}{l}\text { I believe that the communication tends to } \\
\text { grievances }\end{array}$ & 0.876 & & & \\
\hline
\end{tabular}

\section{Internal Consistency Reliability}

The assessment of internal consistency reliability is measured by the value of Cronbach's Alpha and composite reliability. It is recommended to report both criteria as Cronbach's Alpha tends to underestimate the internal consistency reliability while composite reliability tends to overestimate the internal consistency reliability (Dancey \& Reidy, 2002). The assessment of dialogic communication constructs' measurement and validation is depicted in Table 2 . The evaluation of internal consistency 
INTERNATIONAL JOURNAL OF ACADEMIC RESEARCH IN BUSINESS AND SOCIAL SCIENCES

Vol. 9, No. 6, June, 2019, E-ISSN: 2222-6990 @ 2019 HRMARS

reliability through Cronbach's Alpha shown that the overall values were ranging from 0.902 to 0.937 which passed the threshold value of 0.7 or higher for good internal consistency measurement (Hair et al., 2017). The values of composite reliability also shown the reliability of measurement since the values exceed the threshold value of 0.7 for exploratory research (Hair et al., 2017).

\section{Convergent Validity}

Convergent validity is necessary to assess whether a measure correlates positively with alternative measures of the same construct (Hair et al., 2017). The indicator reliability of the measurement is achieved since all the items' loadings have passed the minimum preferred value of 0.7 (Henseler, Ringle \& Sarstedt, 2015) as shown in Table 2 indicating associated indicators have much in common. Additionally, the measurements achieved acceptable convergent validity since all of the measurements' AVE values are larger than 0.5 showing a good communality of a construct (Hair et al., 2017).

\section{Discriminant Validity}

Discriminant validity measures whether a construct is truly different from other constructs by empirical standards (Hair et al., 2017). The constructs' measurements exhibit discriminant validity as analyzed through Fornell-Larcker Criterion. The analysis showed that the values of AVE squared root in diagonal were greater than the squared correlation with other constructs in off-diagonal as depicted in Table 3.

\section{Establishing Norm of Dialogic Communication Scale}

The establishment of the norm for dialogic communication scale is made after the thresholds of various reliability and validity are met as discussed earlier. This is also parallel to the recommended procedures for scale measurement and validation (Churchill, 1979). This dialogic communication scale's norm can be applied particularly to those individuals who are experiencing dialogic communication on a particular change. This scale is specifically developed and tested by employees' in education institution enabling this scale norms to help practitioners assess the relative standing of an individual comparison to others on the targeted scale (Henseler, Ringle \& Sarstedt, 2015). Change practitioners and communication practitioners can use this scale to bolster their understanding and standing of employees' perception on dialogic communication and to take necessary actions to improve the communication.

Table 3: Fornell-Larcker Criterion

\begin{tabular}{lccccc}
\hline & $\begin{array}{c}\text { Commitmen } \\
\mathbf{t}\end{array}$ & Empathy & Mutuality & Propinquity & Risk \\
\hline Commitment & 0.970 & & & & \\
Empathy & 0.748 & 0.926 & & & \\
Mutuality & 0.620 & 0.778 & 0.880 & & \\
Propinquity & 0.708 & 0.864 & 0.815 & 0.923 & \\
Risk & 0.831 & 0.790 & 0.663 & 0.750 & 0.904 \\
\hline
\end{tabular}


INTERNATIONAL JOURNAL OF ACADEMIC RESEARCH IN BUSINESS AND SOCIAL SCIENCES

Vol. 9, No. 6, June, 2019, E-ISSN: 2222-6990 @ 2019 HRMARS

\section{Discussion}

\section{Implications for Research}

The findings obtained from the scale measurement and validation provides sound theoretical development for dialogic communication construct. First, the dialogic communication construct is empirically tested as five dimensions constructs which encompassed mutuality, propinquity, empathy, commitment and risk as specified by the literature and the pioneer. It was found that all of the five dimensions have distinct statistical output as implied through exploratory factor analysis. Each of the constructs has a different placement in the components although four items were later deleted due to poor factor loading. This unique property among the dimensions has unlocked a deeper level of analysis on dialogic communication as such future research may look on the strengths of the dimensions that may influence dialogic communication the most or perhaps to look on the inextricable relationships among the constructs. Comparatively, the qualitative study on the assessment of dialogic communication found that communicators were most likely to engage in empathy, followed by propinquity, mutuality, commitment and risk (Seow \& Malikka, 2014).

Second, the placement of dialogic communication in organizational change may posit a promising research and practice. It may also yield insightful discovery by considering dialogic communication as the antecedents of change or a mediator of change in explaining a successful organizational outcome. A previous research that was done qualitatively found that resistance to change among employees subsided with the presence of dialogic communication elements (Heuvel et al., 2016). As overlapping efforts will occur resulting in partially anticipated outcomes, there is a lot of interactions need to be attended in further understanding dialogic communication.

\section{Implications for Practice}

The empirical findings provide additional cues for dialogic communication practices. Change and communication practitioners can use this overall dialogic communication scale to differentiate between the other form of communication. Specifically, it is imperative for them to differentiate between monologic communication and dialogic communication. Since dialogic communication was proven to bridge successful organizational change (Heuvel et al., 2016), change practitioners can now be able to assess each of the dimensions separately with more substantial measurement as a whole construct. Practitioners can also re-evaluate and customize the approach of dialogic communication wherein if one of the dimensions was evaluated and perceived as poorly by the employees or by any other affected parties. The ability to segment dialogic communication tally to the current needs of organizational change will be beneficial for the management to execute a good change communication approach.

Moreover, management can balance the tradeoff between cost and communication. Each change initiative is unique than the others and thus the intensity of dialogic communication needs may be different than the others. In the setting whereby the change is monumental, dialogic communication approach may need to be substantial and may require additional cost to execute. Additionally, leadership will also influence communication outcome. For instance, empathy is the prevailing construct of dialogic communication in the presence of sustainable leadership (Seow \& Malikka, 2014). Leaders who practice dialogic communication will amplify the likelihood of success in 
INTERNATIONAL JOURNAL OF ACADEMIC RESEARCH IN BUSINESS AND SOCIAL SCIENCES

Vol. 9, No. 6, June, 2019, E-ISSN: 2222-6990 (C) 2019 HRMARS

organizational change. Thus, practitioners may enhance guidelines for effective dialogic communication approach.

\section{Limitations}

Although the dialogic communication scale was developed and validated through rigorous procedures of scale development, there are obvious limitations which future research needs to take into consideration when applying this scale. First, the measured items were generated strictly from the literature review with content validated from five samples of the population. Further enhancement on enriching the constructs measurement by adding additional item is also needed as this test only conducted on a preliminary basis.

Second, future research should also need to cross-validate the measurement in different population setting to further assess the consistency of the measurement as to raise the reliability and validity of the instrument. A test-retest examination is thus needed to check the correlation of the proposed dialogic communication scale measured at different time period to ensure a more robust scale validity of the five dimensions.

Third, this dialogic communication scale is validated via a non-probability sampling technique. The basis of generalizability on the findings should be interpreted with caution. Future findings might anticipate different outcomes of the measurement. Therefore, future studies may need to consider stricter sampling via any probability sampling technique in terms of demographic distribution such as age, gender or education (Fowler, 2002). A probabilistic sampling representative sample will directly reduce the bias and improve the external validity of future findings.

\section{Conclusion}

For an organization to have successful change initiatives, proper communication is imperative. An organization needs to be alert to the broad provisions and communications tools, approaches and strategies available when making the change since the nature of communication will influence the change initiatives (Johansson \& Heide, 2008). Although there are diversities of organizational change, communication management and organizational change are also inextricably related (Flower, 1962). As pointed out in the research gap of this research, this finding contributed to the subject of scarcity on theoretical development of dialogic communication's dimensions (Seow \& Malikka, 2014) that was further developed through the instrumental grid of dialogic communication nature by reference (Kent \& Taylor, 2002). Although there are many forms of communication, dialogic communication seems to be more effective in managing organizational change (Heuvel et al., 2016). The avenue of dialogic communication's influence in organizational change continues to be promising.

\section{Acknowledgement}

The authors deeply express gratitude towards Ministry of Higher Education Malaysia for entrusting FRGS (Fundamental Research Grant) - 600-IRMI/FRGS 5/3 (075/2017) to fund this study.

\section{Corresponding Author}

Syed Jamal Abdul Nasir Syed Mohamad

Arshad Ayub Graduate Business School, Universiti Teknologi MARA (UiTM), Malaysia 
INTERNATIONAL JOURNAL OF ACADEMIC RESEARCH IN BUSINESS AND SOCIAL SCIENCES

Vol. 9, No. 6, June, 2019, E-ISSN: 2222-6990 (C) 2019 HRMARS

Email: syedjamal145@salam.uitm.edu.my

\section{References}

Bakhtin, M. M. (1986), Speech Genres and Other Essays, University of Texas Press, Austin, Texas.

Bentley, J. M. (2012), Applying dialogic public relations theory to public relations education, Teaching Journalism \& Mass Communication, 2 (1), 1-11.

Botan, C. (1997), Ethics in strategic communication campaigns: the case for a new approach to public relations, Journal of Business Communication, 34 (2), 187-201.

Bruning, S., Dials, M. and Shirka, A. (2008), Using dialogue to build organization-public relationships, engage publics, and positively affect organizational outcomes, Public Relations Review, 34 (1), 25-31.

Buber, M. (1967), The Knowledge of Man, Harper \& Row, New York, NY. Stewart, J. (1978), Foundations of dialogic communication, Quarterly Journal of Speech, 64 (2), 183-201.

Caldwell, R. (1993), Employee involvement and communication, Journal of Strategic Change, 2 (3), 135-138.

Carpenter, S., Takahashi, B., Lertpratchya, A. P., \& Cunningham, C. (2016). Greening the campus: a theoretical extension of the dialogic communication approach. International Journal of Sustainability in Higher Education, 17 (4), 520-539.

Churchill, G.A. (1979), A paradigm for developing better measures of marketing constructs, Journal of Marketing Research, 16 (1), 64-73.

Dancey, C. P., \& Reidy, J. (2002). Statistics without maths for psychology: using SPSS for Windows. Harlow: Prentice Hall.

Flower, O. D. (1962). Overcoming resistance to change [Film]. Beverly Hills, CA: Roundtable Productions.

Fowler, F. J. (2002), Survey Research Methods, Sage, Thousand Oaks, CA.

Hair, J. F., Black, W. C., Babin, H. J., \& Anderson, R. E. (2010). Multivariate Data Analysis (7th ed.). New Jersey: Prentice Hall.

Hair, J. F., Hult, G. T., Ringle, C. M., \& Sarstedt, M. (2017). A primer on partial least squares structural equation modelling (PLS-SEM). Los Angeles; London; New Delhi; Singapore; Washington DC; Melbourne: Sage.

Henseler, J., Ringle, C. M., \& Sarstedt, M. (2015). A new criterion for assessing discriminant validity in variance-based structural equation modelling. Journal of the academy of marketing science, 43(1), 115-135.

Heuvel, S., Schalk, R., Freese, C., \& Timmerman, V. (2016), What's in it for me? Managerial perspective on the influence of the psychological contract on attitude towards change, Journal of Organizational Change Management, 29 (2).

Jasmin, G., Jan, B., Christian, H., \& Jeremy, M. (2014). Higher education and sustainable development, Accounting, Auditing \& Accountability Journal, 27 (2), 218-233.

Johansson, C., \& Heide, M. (2008). Speaking of change: three communication approaches in studies of organizational change. Corporate Communications: An International Journal, 13 (3), 288305. 
INTERNATIONAL JOURNAL OF ACADEMIC RESEARCH IN BUSINESS AND SOCIAL SCIENCES

Vol. 9, No. 6, June, 2019, E-ISSN: 2222-6990 (C) 2019 HRMARS

Kent, M. and Taylor, M. (2002), Toward a dialogic theory of public relations, Public Relations Review, 28 (1), 21-37.

Lawrence, P. R. (1954). How to deal with resistance to change. Harvard Business Review, 32 (3), 4957.

MacKenzie, S. B., Podsakoff, P. M., \& Podsakoff, N. P. (2011). Construct measurement and validation procedures in MIS and behavioural research: Integrating new and existing techniques. MIS Quarterly, 35(2), 293-334.

Matos, P. M. S., \& Mark, E. (2014). Improving change management: How communication nature influences resistance to change. Journal of Management Development, 33(4), 324-341.

Plewes, J. (2014). Change Fatigue: The Hidden Sleeper in Change Failure. Retrieved January 11, 2018, from https://www.morganmckinley.com.au/article/change-fatigue-hidden-sleeper-changefailure

Quirke, B. (1995), Communicating Change. McGraw-Hill, New York, NY.

Roni, M. S. (2014). Introduction to SPSS. Edith Cowan University, SOAR Centre, Australia.

Seow, T. L. \& Mallika H. D., (2014), Dialogic communication and media relations in nongovernmental organizations, Journal of Communication Management, 18 (1), $80-100$.

Stewart, J. (1978). Foundations of dialogic communication, The Quarterly Journal of Speech (64), 197198.

Wong, K. K. (2013). Partial Least Squares Structural Equation Modeling (PLS-SEM) Techniques Using SmartPLS. Marketing Bulletin, 24 (1), 1-32. 